\title{
Effect of Ridge Morphology on Guided Bone Regeneration Outcome: Conventional Tomographic Study
}

\author{
Sang-Hoon Park, ${ }^{*}$ Sharon L. Brooks, ${ }^{\dagger}{ }^{\dagger}$ Tae-Ju Oh, ${ }^{\dagger}$ and Hom-Lay Wang ${ }^{\dagger}$
}

Background: This study retrospectively analyzed conventional tomograms to estimate the prognostic value of the cross-sectional ridge morphology on the clinical outcome of guided bone regeneration (GBR).

Methods: Presurgical conventional tomograms of 23 single-implant sites were analyzed retrospectively in 20 patients. All sites had a non-space-making buccal dehiscence defect associated with the subsequently placed dental implant. Simultaneous GBR procedures were performed, and 6-month clinical outcomes were assessed. Measurements at baseline and at the 6-month reentry included defect height (from smooth-rough junction to the most apical part of the defect) and horizontal bone gain at three locations (smooth-rough junction, middle, and most apical portion of the defect). All measurements were taken from a reference template. Tomographic parameters included the implant-associated ridge angle and width measured at $6 \mathrm{~mm}$ below the alveolar crest and at the most apical point of the implant. Implant exposure and the presence of the barrier membrane were controlled for during statistical analyses.

Results: The presurgical ridge angle had a significant negative correlation with the percentage of defect height reduction $(r=-0.621 ; P=0.002)$ and horizontal bone gain $(\mathrm{r}=-0.469 ; P=0.024)$. This difference remained significant even after controlling for implant/membrane exposure $(P=$ 0.001 and $P=0.019$, respectively). A statistically and clinically greater percentage of defect height reduction was observed for ridge angles $<28^{\circ}(P=0.023)$. Ridge width did not have a significant effect on the regenerative outcome.

Conclusion: Cross-sectional presurgical ridge angles may have prognostic value in estimating the outcome of simultaneous GBR. J Periodontol 2009;80:1231-1236.

\section{KEY WORDS}

Bone regeneration; dental implant; morphology; tomography.

\footnotetext{
* Department of Periodontics, Dental School, Baltimore College of Dental Surgery University of Maryland, Baltimore, MD.

$\dagger$ Department of Periodontics and Oral Medicine, School of Dentistry, University of Michigan, Ann Arbor, MI.

† Department of Radiology, Medical School University of Michigan.
}

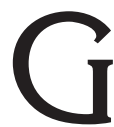
uided bone regeneration (GBR) has been a good alternative treatment option for augmenting ridge deficiency. Prognostic factors suggested for successful bone augmentation include the absence of membrane/ implant exposure, ${ }^{1-6}$ primary stability of the implant, ${ }^{7}$ defect morphology, ${ }^{3,8,9}$ and a passive tension flap. ${ }^{10}$ However, these can only be determined intrasurgically or post-surgically. Several investigators $^{11,12}$ suggested various types of ridge-augmentation procedures based upon the presurgical ridge width. It was suggested that small to moderate horizontal bone loss of 3 to $6 \mathrm{~mm}$ in the HVC (horizontal, vertical, and combination) classification ${ }^{11}$ or division $B$ (barely sufficient) ${ }^{12}$ bone, if the ridge width (2.5 to $5.0 \mathrm{~mm}$ ) is barely sufficient for $4.0-\mathrm{mm}$ diameter dental implants, is a good indication for GBR treatment. These classifications indicate implicitly that the ridge morphology may influence the regenerative outcome. However, to the best of our knowledge, no study has assessed the prognostic value of the ridge morphology on GBR outcome.

Conventional and computed tomography provide cross-sectional images with valuable diagnostic information for an implant treatment plan. ${ }^{13-16}$ These include a presurgical survey of surgical anatomy ${ }^{17}$ and measurement of preoperative bone mineral density as an indirect measurement of bone quality, ${ }^{18} \mathrm{com}$ puter-guided navigation, ${ }^{19}$ fabrication of 
surgical guides, ${ }^{20}$ and postoperative imaging and evaluation of the healing pattern of regenerative procedures. ${ }^{21,22}$ Despite diagnostic benefits, their prognostic properties have not been discussed in the literature.

Therefore, the aim of this 6-month retrospective study was to assess the prognostic values of the conventional tomographic cross-sectional ridge morphology (in particular, ridge angle and width) on the regenerative outcome around non-space-making implant-associated buccal dehiscence defects. Information obtained from this study will be useful for making a presurgical decision about surgical-augmentation procedures.

\section{MATERIALS AND METHODS}

This study analyzed the cross-sectional view of the conventional tomograms obtained from our previous randomized controlled trial of simultaneous GBR. ${ }^{23}$ In our previous study, ${ }^{23}$ each implant site with a 1 -walled, non-space-making, implant-associated buccal dehiscence defect was augmented with the sandwich bone-augmentation technique ${ }^{24}$ and randomly assigned to one of three membrane groups: acellular dermal matrix, ${ }^{\S}$ bovine collagen,\| and periosteum alone.

Prior to the implant placement, conventional tomograms of 23 single-implant sites, in both maxillary and mandibular arches, were obtained form 20 patients (12 females and eight males). The ages of the research subjects ranged from 28 to 71 years. All subjects signed an informed consent form, which had been reviewed and approved by the Institutional Review Board at the University of Michigan, Ann Arbor, Michigan. All participants were older than 18 years of age and systemically healthy. To be included in the study, the subjects had to satisfy the following inclusion criteria: patients requiring a single tooth replacement with a dental implant, insufficient horizontal bone width associated with the potential implant site, and all sites being edentulous for $>6$ months. All subjects completed an initial phase of periodontal therapy, if needed, and demonstrated good oral hygiene. Subjects with any medical contraindications for implant surgery were excluded from the study. In addition, heavy smokers ( $>10$ cigarettes/day) were excluded. The use of human subjects in this study was reviewed and approved by the Health Science Institutional Review Board of the University of Michigan. This study was conducted from 2003 to 2006.

\section{Clinical Parameters}

The regenerative outcomes of 23 implant sites with previous simultaneous ridge augmentation were included for analysis. Using a reference template, defect height and depth were measured prior to the grafting procedure and at 6 months during the second-stage surgery. The mean percentage of defect height reduction was calculated as the difference between the distance from the most apical portion of the defect to the smooth-rough junction of the implant at baseline and at the 6-month reentry. To calculate the horizontal bone gain, the baseline and 6-month defect depths were measured at three distances from the reference template: most apical, middle, and smooth-rough junction.

\section{Conventional Tomography Analysis}

Prior to the implant placement, three cross-sectional tomographic images (anterior, central, and posterior) were obtained for all implant sites, each with a 3-mm image layer, using a computer-controlled extraoral imaging system ${ }^{\text {I }}$ and a custom imaging guide. The central section was used for measurement and statistical analysis. A certified radiologist (SLB) traced the outline of the ridge on an acetate paper attached to the film. A magnification factor of $40 \%$ was used for an adjusted value during calculation, based on data from the manufacturer. The ridge width was measured at $6 \mathrm{~mm}$ below the crest, perpendicular to the central axis of the ridge. The ridge angle $(\alpha)$ was measured between two lines connecting two points on the buccal and lingual surface, one at $6 \mathrm{~mm}$ below the crest and the other $(\chi)$ at the most apical point of the implant placed (10 or $13 \mathrm{~mm}$; Fig. 1).

\section{Statistical Analyses}

The implant was the unit of analysis. The dependent variables were the mean regenerated horizontal bone gain and the percentage of defect height reduction at the 6 -month reentry. Factors considered were the ridge width and angle. Implant exposure and the presence of different types of membranes were included as compounding factors. A two-tailed Pearson correlation was performed to show the relationship between independent variables (i.e., ridge width and ridge angle) and treatment outcome (i.e., mean horizontal bone gain and percentage of defect height reduction). Regression analysis was performed to test the effect of ridge width and angle on the regenerative outcome when the incidence of implant exposure and types of membranes were controlled. The independent sample $t$ test was performed at $25 \%, 50 \%$, and $75 \%$ quartiles of the sample to find the critical angle that results in a statistically significant difference in the treatment outcomes. The significance was determined at $P<0.05$.

\footnotetext{
$\S$ AlloDerm GBR, BioHorizons, Birmingham, AL.

BioMend Extend, Zimmer Dental, Carlsbad, CA

I Orthopantomograph OP 100, Instrumentarium, Imaging Division, Tuusula, Finland.
} 


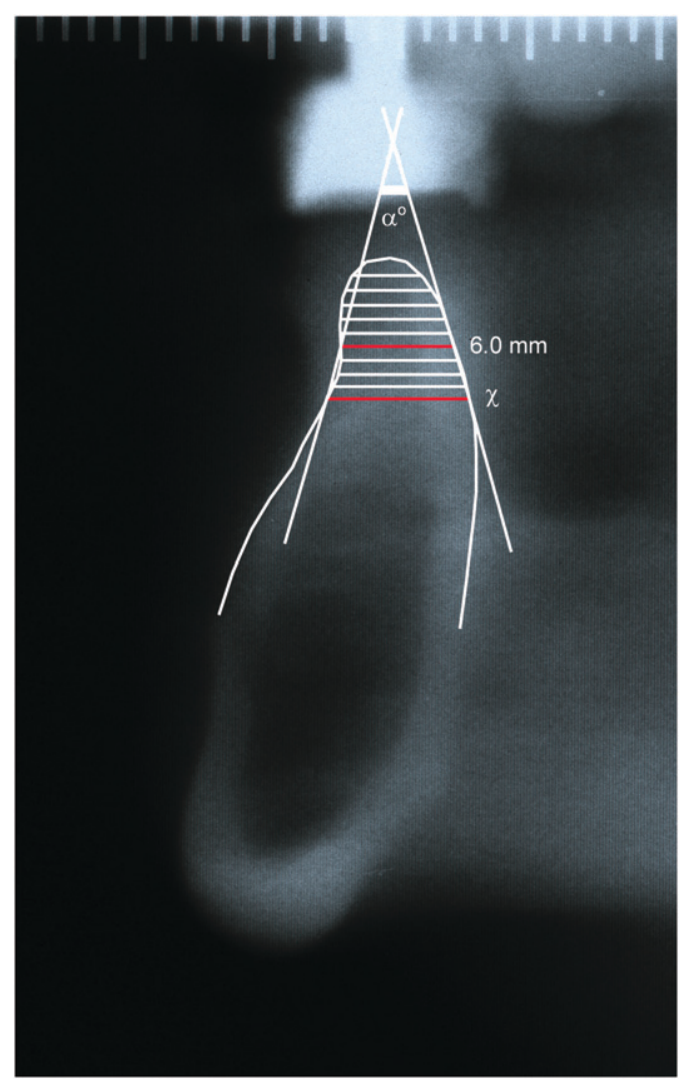

Figure I.

Angle $\alpha$ formed between two lines connecting two points $6.0 \mathrm{~mm}$ and $\chi$ (implant length $=10$ or $13 \mathrm{~mm}$ ) below crest.

\section{RESULTS}

All implants osseointegrated successfully in this study. Two independent variables, ridge angle and width, were evaluated for their effect on GBR outcome. Baseline defect heights were not significantly different among the three treatment groups $(P=$ 0.858).

All treatment groups had a significant reduction in the percentage of defect height and horizontal bone gain: $70.4 \% \pm 20.6 \%$ and $1.5 \pm 0.6 \mathrm{~mm}$ (Table 1 ). The mean ridge angle and width of the presurgical implant site were $28.8^{\circ} \pm 17.1^{\circ}$ and $5.3 \pm 1.2 \mathrm{~mm}$, respectively. Pearson correlation revealed a significant negative correlation between ridge angle and defect height reduction $(\mathrm{r}=-0.621 ; P=0.002)$. Regression analysis, controlling for implant exposure and presence/absence of membrane, also revealed a statistically significant percentage of defect height reduction $(\mathrm{B}=-0.664 ; P=0.001)$.

The presurgical ridge angle from the tomographic cross-sectional image was categorized as a narrow or a wide angle at $25 \%, 50 \%$, and $75 \%$ quartiles (Table 2 ; Fig. 2). At 6 months, a ridge angle $<28^{\circ}$ resulted in a statistically significantly greater percentage of defect height reduction than a ridge angle $>28^{\circ}(P=0.023$; $78.0 \% \pm 17.1 \%$ versus $62.2 \% \pm 21.6 \%)$. The strength of the linear relationship between the ridge angle and \% height reduction was mild to moderate ( $\mathrm{R} \mathrm{Sq}$ Linear $\left.\left[R^{2}\right]=0.386\right)$. No significant effect of the ridge angle was seen when horizontal bone gain was considered a treatment outcome.

The ridge width at $6 \mathrm{~mm}$ below the alveolar crest and at the most apical point of the implant did not have any statistically significant correlation with treatment outcome. The same insignificant association remained even after controlling for implant exposure and the presence of membrane.

\section{DISCUSSION}

The purpose of this 6 -month retrospective study was to investigate the prognostic value of the presurgical ridge morphology on the regenerative outcome around a dental implant. Statistical analyses controlled for implant exposure and the presence of bioabsorbable membranes because these were found to be the major compounding factors with regard to the regenerative outcome. ${ }^{1-6,23}$ Furthermore, all cases were a delayed implant placement with simultaneous GBR in non-space-making 1 -walled defects. Therefore, the case selection criteria were reasonably specific.

It has been speculated that the ridge morphology may influence the regenerative outcome in various ways. Clinically, it may affect the depth of the vestibule, flap tension, and subsequent wound stability after closure of the wound. In addition, intramarrow penetration provides angiogenesis and undifferentiated mesenchymal cells that are essential for GBR. ${ }^{25-29}$ Hence, we postulated the use of ridge angle and width to estimate total available bone volume and bone marrow. We hypothesized that the presurgical ridge angle and width might be used as prognostic criteria for predicting the regenerative outcome of simultaneous GBR.

The implant length was used as a reliable reference point in estimating the ridge morphology. In all of the cases in this study, the ridge maintained a uniform shape down to the most apical point of the implant, beyond which the ridge became very tortuous. Ridge width was measured at two levels: at $6 \mathrm{~mm}$ and at the most apical point of the implant below the crest. The former value was chosen to represent the middle of the average implant length most commonly used in practice. The latter value represents the ridge width of cancellous bone that remains intact after implant placement. The same reference points were used to measure the angle of the implant-associated ridge.

Regression analysis and Pearson correlation revealed a significant negative relationship between ridge angle and the percentage of defect height 
reduction. The percentage of defect height reduction became significantly greater when the ridge angle was $<28^{\circ}$. A narrow angle in the maxillary anterior region is often accompanied by a greater vestibular depth. It remained statistically significant even after controlling the membrane/implant exposure. This suggests that uniform ridge thickness (cylindric shape) is a more important factor for regeneration than a wide bone base (conical shape). It can be speculated that the pressure and flap tension over a uniform cylindricshaped ridge are less than those over a wide-based conical-shaped ridge. In the latter, the likelihood of having greater tension at the crestal portion of the augmented graft is much greater than for a narrow-

Table I.

\section{Effect of Ridge Angle and Width on GBR Outcomes}

\begin{tabular}{lccc}
\hline Parameter & & Ridge Angle & Ridge Width \\
\hline $\mathrm{n}$ & & 23 & 23 \\
Mean $\pm \mathrm{SD}$ & & $28.8 \pm 17.1^{\circ}$ & $5.3 \pm 1.2 \mathrm{~mm}$ \\
Defect height reduction (\%; mean \pm SD) & & $70.4 \pm 20.6$ \\
Pearson correlation & $P(r)$ & -0.621 & 0.033 \\
& $P$ value & $0.002^{*}$ & 0.880 \\
Regression & Beta & -0.664 & 3.311 \\
& SE & 0.179 & 3.491 \\
& $P$ value & $0.001^{\dagger}$ & 0.355 \\
Horizontal bone gain (mm; mean \pm SD) & & & \\
Pearson correlation & $P(r)$ & -0.469 & -0.090 \\
Regression & $P$ value & 0.024 & 0.682 \\
& Beta & -0.0164 & 0.0462 \\
& SE & 0.006 & 0.112 \\
& $P$ value & 0.019 & 0.685 \\
\hline
\end{tabular}

$\mathrm{SE}=$ standard error.

* Correlation significant at the 0.01 level (two-tailed).

$\dagger$ Regression analysis performed with implant exposure and presence of membrane controlled. angled cylindric-shaped ridge. This may contribute to an increased risk for opening of the incision line during the healing period. However, the ridge angle did not make a significant difference in the horizontal bone gain after controlling for the presence and/or absence of membrane. This observation agrees, in part, with our previous finding that the presence of membrane was the main factor influencing horizontal bone gain. ${ }^{23}$

The presurgical width did not significantly influence the treatment outcome. We measured the ridge width at $6 \mathrm{~mm}$ and at the most apical point of the implant. Neither measurement had a significant influence on the clinical outcome. Two speculations can be made. First, because a significant amount of bone marrow was removed during osteotomy site preparation, pretreatment measurements of the implant-associated ridge width may not have estimated the actual bone marrow available during the post-implantation healing period. Therefore, the ridge width at the apical point of the implant was measured to represent the amount of bone marrow remaining intact after implant placement. However, no significant effect was found at this depth, which suggests that bone marrow may not be directly associated with the actual regenerative outcome. Second, the ridge widths that we included in our study ranged

\section{Table 2.}

\section{Narrow Versus Wide Ridge Angle in Relation to Percentage of Defect Height Reduction and Horizontal Bone Gain}

\begin{tabular}{|c|c|c|c|c|}
\hline Parameter & Ridge-Angle Class & $\mathrm{n}$ & $\begin{array}{l}\text { Baseline Defect Height } \\
\quad(\mathrm{mm} ; \text { mean } \pm \mathrm{SD})\end{array}$ & $\begin{array}{l}\text { Defect Height Reduction } \\
\quad(\% ; \text { mean } \pm \mathrm{SD})\end{array}$ \\
\hline \multirow[t]{2}{*}{ Defect height reduction (\%) } & $\begin{array}{c}\text { Narrow }<28^{\circ} \\
\text { Wide } \geq 28^{\circ} \\
P \text { value }\end{array}$ & $\begin{array}{l}12 \\
11\end{array}$ & $\begin{array}{c}7.1 \pm 3.3 \\
5.1 \pm 2.0 \\
0.103\end{array}$ & $\begin{array}{c}78.0 \pm 17.1 \\
62.2 \pm 21.6 \\
0.023\end{array}$ \\
\hline & & & $\begin{array}{l}\text { Baseline Horizontal Bone } \\
\quad(\mathrm{mm} \text {; mean } \pm \mathrm{SD})\end{array}$ & $\begin{array}{l}\text { Horizontal Bone Gain } \\
\quad(\mathrm{mm} \text {; mean } \pm \mathrm{SD})\end{array}$ \\
\hline Horizontal bone gain (mm) & $\begin{array}{c}\text { Narrow }<28^{\circ} \\
\text { Wide } \geq 28^{\circ} \\
P \text { value }\end{array}$ & $\begin{array}{l}12 \\
11\end{array}$ & $\begin{array}{l}0 \\
0 \\
0\end{array}$ & $\begin{array}{c}1.6 \pm 0.7 \\
1.4 \pm 0.5 \\
0.478\end{array}$ \\
\hline
\end{tabular}




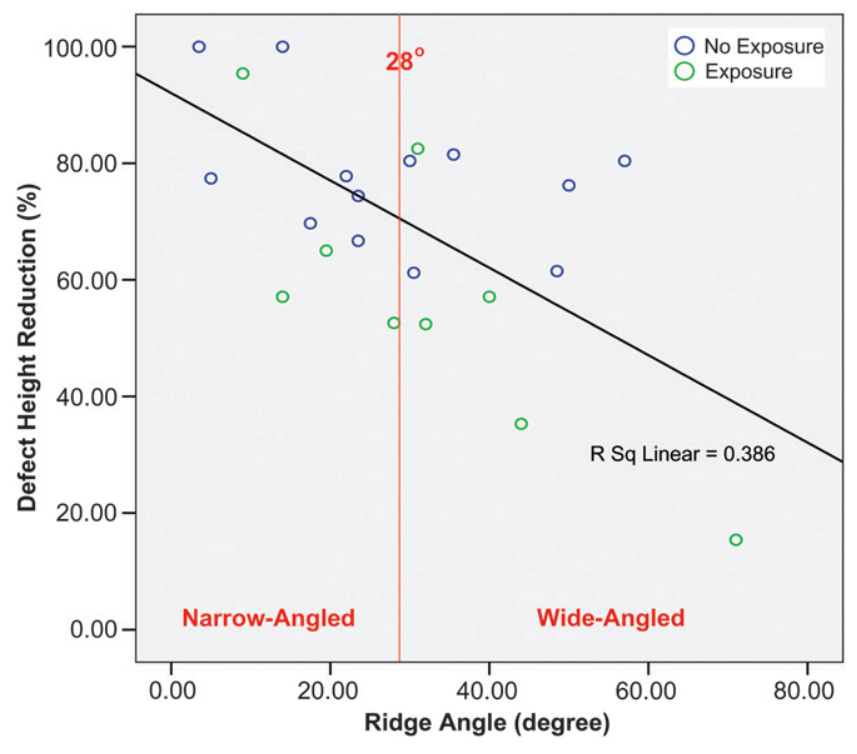

Figure 2.

Effect of ridge angle on percentage of defect height reduction. $R$ Sq Linear = strength of linear relationship; $0 \leq R^{2}$ (coefficient of determination) $\leq 1$.

from 4.1 to $6.5 \mathrm{~mm}$. To the best of our knowledge, no study has determined the minimal bone width (marrow) necessary for sufficient bone regeneration. Hence, we could not make a conclusion with regard to the effect of the ridge width on the regenerative outcome.

\section{CONCLUSIONS}

Assessment of the cross-sectional ridge morphology on conventional tomograms may offer additional prognostic value when a simultaneous regenerative procedure is planned around an implant dehiscence defect. This information may provide additional value in borderline ridge augmentation cases if a decision has to be made between block graft and simultaneous GBR.

A uniform cylindric-shaped ridge with a ridge angle $<28^{\circ}$ was associated with a significant percentage of defect height reduction compared to a wide-angled conical-shaped ridge. Horizontal bone gain remained unaffected by the ridge morphology. Overall, ridge shape seemed to be a more significant factor than ridge width.

\section{ACKNOWLEDGMENTS}

This study was partially supported by the University of Michigan Periodontal Graduate Student Research Fund. The authors report no conflicts of interest related to this study.

\section{REFERENCES}

1. Simion M, Baldoni M, Rossi P, Zaffe D. A comparative study of the effectiveness of e-PTFE membranes with and without early exposure during the healing period. Int J Periodontics Restorative Dent 1994; 14:166-180.

2. Lekholm U, Becker W, Dahlin C, Becker B, Donath K, Morrison E. The role of early versus late removal of GTAM membranes on bone formation at oral implants placed into immediate extraction sockets. An experimental study in dogs. Clin Oral Implants Res 1993; 4:121-129.

3. Zitzmann NU, Naef R, Schärer P. Resorbable versus nonresorbable membranes in combination with BioOss for guided bone regeneration. Int J Oral Maxillofac Implants 1997; 12:844-852.

4. Lorenzoni M, Pertl C, Keil C, Wegscheider WA. Treatment of peri-implant defects with guided bone regeneration: A comparative clinical study with various membranes and bone grafts. Int $J$ Oral Maxillofac Implants 1998;13:639-646.

5. Machtei EE. The effect of membrane exposure on the outcome of regenerative procedures in humans: A meta-analysis. J Periodontol 2001;72:512-516.

6. Moses O, Pitaru S, Artzi Z, Nemcovsky CE. Healing of dehiscence-type defects in implants placed together with different barrier membranes: A comparative clinical study. Clin Oral Implants Res 2005;16:210-219.

7. Wang HL, Boyapati L. "PASS" principles for predictable bone regeneration. Implant Dent 2006;15:8-17.

8. Zitzmann NU, Schärer P, Marinello CP. Factors influencing the success of GBR. Smoking, timing of implant placement, implant location, bone quality and provisional restoration. J Clin Periodontol 1999;26: 673-682.

9. Zitzmann $N U$, Schärer P, Marinello CP. Long-term results of implants treated with guided bone regeneration: A 5-year prospective study. Int J Oral Maxillofac Implants 2001;16:355-366.

10. Buser D, Brägger U, Lang NP, Nyman S. Regeneration and enlargement of jaw bone using guided tissue regeneration. Clin Oral Implants Res 1990;1:22-32.

11. Wang HL, Al-Shammari K. HVC ridge deficiency classification: A therapeutically oriented classification. Int $J$ Periodontics Restorative Dent 2002;22:335-343.

12. Misch CE. Contemporary Implant Dentistry, 2nd ed. St. Louis: Mosby; 1999:97-99.

13. Bolin A, Eliasson S, von Beetzen M, Jansson L. Radiographic evaluation of mandibular posterior implant sites: Correlation between panoramic and tomographic determinations. Clin Oral Implants Res 1996; 7:354-359.

14. Tyndall DA, Brooks SL. Selection criteria for dental implant site imaging: A position paper of the American Academy of Oral and Maxillofacial Radiology. Oral Surg Oral Med Oral Pathol Oral Radiol Endod 2000; 89:630-637.

15. Bou Serhal C, Jacobs R, Persoons M, Hermans R, van Steenberghe D. The accuracy of spiral tomography to assess bone quantity for the preoperative planning of implants in the posterior maxilla. Clin Oral Implants Res 2000;11:242-247.

16. Schropp L, Wenzel A, Kostopoulos L. Impact of conventional tomography on prediction of the appropriate implant size. Oral Surg Oral Med Oral Pathol Oral Radiol Endod 2001;92:458-463. 
17. Bou Serhal C, van Steenberghe D, Quirynen M, Jacobs $\mathrm{R}$. Localization of the mandibular canal using conventional spiral tomography: A human cadaver study. Clin Oral Implants Res 2001;12:230-236.

18. Norton MR, Gamble C. Bone classification: An objective scale of bone density using the computerized tomography scan. Clin Oral Implants Res 2001;12:79-84.

19. Kramer FJ, Baethge C, Swennen G, Rosahl S. Navigated vs. conventional implant insertion for maxillary single tooth replacement. Clin Oral Implants Res 2005; 16:60-68.

20. Van Steenberghe D, Malevez C, Van Cleynenbreugel J, et al. Accuracy of drilling guides for transfer from three-dimensional CT-based planning to placement of zygoma implants in human cadavers. Clin Oral Implants Res 2003;14:131-136.

21. Ito K, Yoshinuma N, Goke E, Arai Y, Shinoda K. Clinical application of a new compact computed tomography system for evaluating the outcome of regenerative therapy: A case report. J Periodontol 2001; 72:696-702.

22. Maréchal M, Luyten F, Nijs J, Postnov A, Schepers E, van Steenberghe D. Histomorphometry and microcomputed tomography of bone augmentation under a titanium membrane. Clin Oral Implants Res 2005; 16:708-714.

23. Park SH, Lee KW, Oh TJ, Misch CE, Shotwell J, Wang HL. Effect of absorbable membranes on sandwich bone augmentation. Clin Oral Implants Res 2008;19:32-41.

24. Wang HL, Misch C, Neiva RF. "Sandwich" bone augmentation technique: Rationale and report of pilot cases. Int J Periodontics Restorative Dent 2004;24: 232-245.

25. Majzoub Z, Berengo M, Giardino R, Aldini NN, Cordioli $G$. Role of intramarrow penetration in osseous repair: A pilot study in the rabbit calvaria. J Periodontol 1999;70:1501-1510.

26. Lundgren AK, Lundgren D, Hämmerle CH, Nyman S, Sennerby L. Influence of decortication of the donor bone on guided bone augmentation. An experimental study in the rabbit skull bone. Clin Oral Implants Res 2000;11:99-106.

27. Nyman R, Sennerby L, Nyman S, Lundgren D. Influence of bone marrow on membrane-guided bone regeneration of segmental long-bone defects in rabbits. Scand J Plast Reconstr Surg Hand Surg 2001; 35:239-246.

28. Slotte C, Lundgren D. Impact of cortical perforations of contiguous donor bone in a guided bone augmentation procedure: An experimental study in the rabbit skull. Clin Implant Dent Relat Res 2002;4:1-10.

29. Nishimura I, Shimizu Y, Ooya K. Effects of cortical bone perforation on experimental guided bone regeneration. Clin Oral Implants Res 2004;15:293-300.

Correspondence: Dr. Sang-Hoon Park, Department of Periodontics, Baltimore College of Dental Surgery, University of Maryland, Dental School, 650 W. Baltimore St. Room 4203, Baltimore, MD 21201. Fax: 410/706-7201; e-mail: spark@umaryland.edu.

Submitted February 12, 2009; accepted for publication March 12, 2009. 